\title{
Relations between cardiothoracic surgeons and industry
}

\author{
Michael J. Mack, MD, ${ }^{a}$ and Robert M. Sade, MD, ${ }^{b}$ for the American Association for Thoracic Surgery Ethics Committee ${ }^{\mathrm{c}}$ and \\ The Society of Thoracic Surgeons Standards and Ethics Committee ${ }^{\mathrm{d}}$ \\ The primary responsibility of specialists in cardiothoracic \\ surgery is caring for the patient. The sine qua non of effec\section{INDUSTRY} \\ RELATIONS BETWEEN PHYSICIANS AND
} tive patient care is the patient's trust, manifested as an unwavering belief that our advice and decisions are driven by the patient's best interest. We are presented daily with real or potential conflicts of interest, such as remuneration for ordering tests or performing procedures, enrolling patients in clinical trials, attending expense-paid, industry-sponsored educational events, or accepting large or small gifts. To serve the best interests of our patients and maintain their trust, we must acknowledge the factors that expose us to risks of subordinating patients' interests to the interests of others, including our own. Some conflicts of interest are inevitable and some are evitable; we can manage conflicts by avoiding those we can and resolving those we cannot avoid in favor of our patients.

Most physicians view themselves as free from bias or conflicts of interest in carrying out their responsibilities to patients. At the same time, however, they see other physicians as being unduly influenced in making patient care decisions by such external factors as gifts from industry. ${ }^{1,2}$ We must always be aware of the universal human trait of self-deception in ourselves. Accepting that we are as subject to self-deception as our fellow professionals and are confronted with many conflicts of interest every day, we may serve our patients and profession best with standards for avoiding or appropriately managing such conflicts.

\footnotetext{
From Cardiothoracic Surgery Associates of North Texas, Cardiopulmonary Research Science and Technology Institute, Dallas, Tex ${ }^{\mathrm{a}}$; the Division of Cardiothoracic Surgery, Department of Surgery, and Institute of Human Values in Health Care, Medical University of South Carolina, Charleston, SC ${ }^{\mathrm{b}}$; the American Association for Thoracic Surgery Ethics Committee (Drs Robert M. Sade, Charleston, SC [chair]; Cary W. Akins, Boston, Mass; Thomas A. D'Amico, Durham, NC; James W. Jones, Houston, Tex; Martin F. McKneally, Toronto, Ontario, Canada; Keith S. Naunheim, St Louis, Mo; and Andrew S. Wechsler, Philadelphia, $\mathrm{Pa})^{\mathrm{c}}$; and The Society of Thoracic Surgeons Standards and Ethics Committee (Drs Robert M. Sade, Charleston, SC [chair]; Mark S. Allen, Rochester, Minn; David N. Campbell, Aurora, Colo; Richard M. Engelman, Springfield, Mass; Mark K. Ferguson, Chicago, Ill; Steven W. Guyton, Seattle, Wash; John W. Hammon, Jr, Winston-Salem, NC; Sidney Levitsky, Boston, Mass; John E. Mayer, Jr, Boston, Mass; Eric N. Mendeloff, Dallas, Tex; Mark B. Orringer, Ann Arbor, Mich; Ross M. Ungerleider, Cleveland, Ohio; Donald C. Watson, Biltmore Forest, NC; and Walter G. Wolfe, Durham, NC). ${ }^{\mathrm{d}}$

Dr Mack discloses a relationship with Edwards Lifesciences, Medtronic, and Maquet. This article is being published simultaneously in The Journal of Thoracic and Cardiovascular Surgery and The Annals of Thoracic Surgery.

Received for publication Feb 3, 2009; accepted for publication Feb 4, 2009.

Address for reprints: Robert M. Sade, MD, Department of Surgery, Medical University of South Carolina, 96 Jonathan Lucas St, Suite 409, PO Box 250612, Charleston, SC 29425 (E-mail: sader@musc.edu).

J Thorac Cardiovasc Surg 2009;137:1047-9

$0022-5223 / \$ 36.00$

Copyright () 2009 by The American Association for Thoracic Surgery and The

Society of Thoracic Surgeons

doi:10.1016/j.jtcvs.2009.02.001
}

About half of the tremendous advances in human wellbeing during the past half-century have been brought to us by drug and device companies' research and development. ${ }^{3}$ Moreover, industry's marketing of new drugs and technologies should not be underappreciated - without effective marketing, introduction of innovations into clinical use would be far slower. To deliver state-of-the-art treatment to our patients most effectively, a collaborative relationship with our colleagues in industry is necessary and desirable. ${ }^{4}$ The many opportunities for collaboration include but are not limited to development of new drugs and invention of new devices, education regarding existing drugs and devices, and assistance to surgeons in maintaining current skills and developing new ones. Cardiothoracic surgeons are eminently qualified to conduct clinical research trials, to provide innovative ideas and feedback regarding the introduction of new technologies, and to serve on scientific advisory boards of medical device and drug companies. Other opportunities for interaction include development of cutting-edge medical technologies, improvement of existing products, and education of surgeons in the safe and effective use of medical technologies. Although surgeons are primarily responsible for ensuring that they acquire the knowledge and skills needed to use new technologies properly, the companies that develop and market those technologies are responsible for providing educational assistance to surgeons when appropriate.

Cardiothoracic surgeons participate in continuing medical education programs and professional meetings to maintain and expand the knowledge and skills necessary to provide optimal patient care. Our academic institutions, training programs, and professional societies play significant roles in these activities, and interaction and collaboration with industry provide a desirable synergy. Collaborative effort often leads to the best clinical outcomes, obtained through the appropriate introduction of new technologies as well as research and evaluation of existing technologies and techniques. Furthermore, education regarding new devices and techniques is part of the Food and Drug Administration's mandate for introduction of safe and effective new drugs and devices into clinical medicine. Pharmaceutical and medical device manufacturers' sponsorship of these functions benefits patients, surgeons, and manufacturers. These relationships, however, can be abused. The ethical standards enumerated here are intended to promote appropriate relations between cardiothoracic surgeons and our colleagues in industry.

\section{CONFLICT OF INTEREST DEFINED}

A conflict of interest occurs when individual's self-interest and an obligation diverge. In the clinical setting, the divergence 
is between a surgeon's self-interest and the obligation to care first for the patient. A potential conflict of interest is present when divergence is possible but has not yet occurred. Stated another way, a conflict of interest exists when professional judgment concerning the well-being of the patient has a reasonable likelihood of being influenced by other interests of the surgeon, to the potential detriment of the patient. The surgeon's interests may be financial but also may involve fame, notoriety, or professional advancement, such as a full partnership in a private practice or tenure in an academic position.

A conflict of interest does not necessarily result in harm to a patient; whether the outcome of a conflict is good or bad depends on how it is managed. Most such conflicts can and should be resolved in favor of benefit to the patient. Perceptions of conflicts of interest are of much less concern than poorly managed conflicts that actually harm patients. A recent study found that public trust in the medical profession is not eroded by real or perceived conflicts in patient care, research, or education. ${ }^{5}$

Examples of relationships in which potential or actual conflicts of interest may exist follow:

- Membership on scientific advisory boards

- Paid consultancy

- Compensation from employment

- Honoraria and speaker fees

- Paid expert testimony

- Gifts

- Travel

- Meals and hospitality

- Intellectual property rights

- Stock ownership and options

\section{THE AMERICAN ASSOCIATION FOR THORACIC SURGERY AND THE SOCIETY OF THORACIC SURGEONS CODES OF ETHICS}

The American Association for Thoracic Surgery and the Society of Thoracic Surgeons have adopted nearly identical codes of ethics, both of which address a broad range of ethical concerns affecting cardiothoracic surgery. ${ }^{6,7}$ The following ethical standards should be understood and interpreted in the context of those codes. Both the codes and these standards necessarily apply specifically to the membership of our cardiothoracic societies; however, cardiothoracic residency program directors would be well advised to require their trainees to follow them as well. In developing this document, similar documents from several other organizations were consulted. ${ }^{8-11}$

\section{ETHICAL STANDARDS FOR CARDIOTHORACIC SURGEONS RELATING TO INDUSTRY*}

1. When caring for patients, members must hold the patient's welfare paramount.

* In these standards, the words should and must connote lesser and greater degrees of obligation, respectively. Both terms denote enforceable ethical standards.
2. Members must prescribe drugs, devices, and treatment solely on the basis of medical considerations and patients' preferences, regardless of any direct or indirect inducements by industry.

3. Members should inform a patient of any conflicts of interest arising from their relationships with or investments in companies that manufacture or supply medications, devices, or therapies to be used for the patient. Any conflict of interest must be resolved in the best interest of the patient.

4. When faced with a conflict of interest that cannot be easily resolved, a member should consult with disinterested colleagues or an institutional ethics committee to determine if an actual or potential conflict of interest is present and if so how to address it.

5. Members should accept no gifts from industry, regardless of value. Drug samples intended only for the use of patients are not considered gifts.

6. Members must accept no direct or indirect financial inducements from industry for using one particular device or drug rather than another or for switching from one manufacturer's product to another. Unacceptable inducements include payment over and above the actual cost of completing postmarketing surveys of drug or device use.

7. Members who enter into a consulting agreement should be able to document the following:

- The consulting service was needed.

- The consulting service was actually provided.

- The payment for consultation was not higher than fair market value.

- No compensation or other incentive was based on the volume or value of business associated with the agreement.

8. Members should disclose their own or their institution's financial relationship with the manufacturer of a drug or device whenever clinical research or experience with a particular procedure or device is presented at a meeting or is published.

9. Members who serve as the principal investigator of any research project should report fully any influence from funding sources on designing the project, controlling access to the data, preparing a presentation or paper, or controlling timing of presentation or publication.

10. Members should accept no remuneration from industry to attend any social functions that have no educational content.

11. Members should not accept any financial support from industry for attendance at any educational event. Residency program directors should ensure that industry grants, which may be extended to residents, are made through the sponsoring institution, not directly to the resident.

12. Members who are speakers at an industry-supported educational event should accept only reasonable honoraria and reimbursement for travel, meals, and lodging; all 
such payments should be made by the conference sponsor, not directly by industry.

13. Members should attend a company-sponsored event only when the major purpose of the event is education and training in the proper use of the company's products; the only financial considerations should be reimbursement for travel, meals, and lodging. Members should not accept reimbursement for attending such an educational event if the event's location constitutes an inducement that is independent of the event's educational value.

\section{References}

1. McKinney WP, Schiedermayer DL, Lurie N, Simpson DE, Goodman JL, Rich EC. Attitudes of internal medicine faculty and residents toward professional interaction with pharmaceutical sales representatives. JAMA. 1990;264:1693-7.

2. Steinman MA, Shlipak MG, McPhee SJ. Of principles and pens: attitudes and practices of medicine housestaff toward pharmaceutical industry promotions. Am J Med. 2001;110:551-7.

3. Ford ES, Ajani UA, Croft JB, Critchley JA, Labarthe DR, Kottke TE, et al. Explaining the decrease in U.S. deaths from coronary disease, 1980-2000. N Engl J Med. 2007;356:2388-98.

4. Stossel TP. A biopsy of financial conflicts of interest in medicine. Surgery. 2008; 143:193-8.
5. Hampson LA, Agrawal M, Joffe S, Gross CP, Verter J, Emanuel EJ. Patients' views on financial conflicts of interest in cancer research trials. $N$ Engl J Med. 2006;355:2330-7.

6. American Association for Thoracic Surgery. Code of ethics [monograph on the Internet]. Beverly (MA): American Association for Thoracic Surgery; 2008 [cited 2009 Jan 8]. Available from: http://www.aats.org/Association/Policies/Code_of_ Ethics.

7. Society of Thoracic Surgeons. Code of ethics [monograph on the Internet]. Chicago: Society of Thoracic Surgeons; 2006 [cited 2009 Jan 8]. Available from http://www.sts.org/sections/aboutthesociety/policies/code $\% 20$ of $\% 20$ ethics/.

8. Council on Ethical and Judicial Affairs, American Medical Association. Opinion 8.061 and addendum: gifts to physicians from industry. In: American Medical Association. Code of medical ethics: current opinions with annotations, 2008-2009. Chicago: American Medical Association; 2008. p. 230-43.

9. American Association of Orthopaedic Surgeons. Standards of professionalism (SOPs) of the American Association of Orthopaedic Surgeons: orthopaedistindustry conflicts of interest [monograph on the Internet]. Rosemont (IL) Association of Orthopaedic Surgeons; 2007 [cited 2009 Jan 8]. Available from: http://www3.aaos.org/member/profcomp/SOPConflictsIndustry.pdf.

10. Pharmaceutical Research and Manufacturers of America. Code on interactions with healthcare professionals [monograph on the Internet]. Washington: Pharmaceutical Research and Manufacturers of America; 2009 [cited 2009 Jan 8]. Available from: http://www.phrma.org/files/PhRMA\%20Marketing\%20Code\%202008.pdf.

11. Advanced Medical Technology Association. Code of ethics on interactions with health care professionals [monograph on the Internet] Washington: Advanced Medical Technology Association; 2005 [cited 2009 Jan 8]. Available from: http://www advamed.org/NR/rdonlyres/FA437A5F-4C75-43B2-A900-C9470BA8DFA7/0/coe with_faqs_41505.pdf. 